Short communication

\title{
Highly selective detection of Epinephrine at oxidized Single-Wall Carbon Nanohorns modified Screen Printed Electrodes (SPEs)
}

\author{
F. Valentini ${ }^{\text {a,* }}$, E. Ciambella ${ }^{a}$, V. Conte ${ }^{\text {a }}$, L. Sabatini ${ }^{\mathrm{b}}$, N. Ditaranto ${ }^{\mathrm{b}}$, F. Cataldo ${ }^{\mathrm{a}, \mathrm{c}}$, \\ G. Palleschi ${ }^{\mathrm{a}}$, M. Bonchio ${ }^{\mathrm{d}}$, F. Giacalone ${ }^{\mathrm{e}, \mathrm{f}}$, Z. Syrgiannis ${ }^{\mathrm{e}}$, M. Prato ${ }^{\mathrm{e}}$ \\ a Dipartimento di Scienze e Tecnologie Chimiche, Università di Roma Tor Vergata, via della ricerca Scientifica 1, 00133 Rome, Italy \\ b Dipartimento di Chimica, Università degli Studi di Bari “Aldo Moro", via Orabona 4, I-70125 Bari, Italy \\ c Actinium Chemical Research srl, via Casilina 1626A, 00133 Rome, Italy \\ d ITM-CNR, Dipartimento di Scienze Chimiche, Università di Padova, via Marzolo 1, I-35131 Padova, Italy \\ e Dipartimento Scienze Chimiche e Farmaceutiche, Piazzale Europa 1, 34127 Trieste, Italy \\ ${ }^{\mathrm{f}}$ Dipartimento di Scienze e Tecnologie Biologiche, Chimiche e Farmaceutiche (STEBICEF), Università degli Studi di Palermo, via delle Scienze s/n, Parco \\ d'Orleans - Ed. 17, 90128 Palermo, Italy
}

\section{A R T I C L E I N F O}

Article history:

Received 4 December 2013

Received in revised form

7 February 2014

Accepted 25 February 2014

Available online 6 March 2014

Keywords:

SWCNHs

Screen Printed Electrodes (SPEs)

Neurotransmitters

Selective detection

\begin{abstract}
A B S T R A C T
Oxidized Single-Wall Carbon Nanohorns (o-SWCNHs) were used, for the first time, to assemble chemically modified Screen Printed Electrodes (SPEs) selective towards the electrochemical detection of Epinephrine (Ep), in the presence of Serotonine-5-HT (S-5HT), Dopamine (DA), Nor-Epineprhine (NorEp), Ascorbic Acid (AA), Acetaminophen (Ac) and Uric Acid (UA). The Ep neurotransmitter was detected by using Differential Pulse Voltammetry (DPV), in a wide linear range of concentration $(2-2500 \mu \mathrm{M})$ with high sensitivity (55.77 $\mathrm{A} \mathrm{M}^{-1} \mathrm{~cm}^{-2}$ ), very good reproducibility (RSD\% ranging from 2 to 10 for different SPEs), short response time for each measurement (only $2 \mathrm{~s}$ ) and low detection of limit (LOD $=0.1 \mu \mathrm{M}$ ). o-SWCNHs resulted in higher analytical performances when compared with other nanomaterials used in literature for electrochemical sensors assembly.
\end{abstract}

(c) 2014 Elsevier B.V. All rights reserved.

\section{Introduction}

Detection of Epinephrine (Ep), an important cathecolamine, in human blood and in the cerebral fluids is of fundamental importance because of its involvement in the neurodegenerative diseases, as Parkinson's and Alzheimer's disorders (Dongen, 1981; Remy et al., 2005). A number of methods were reported for the determination of catecholamines by spectrophotometry (Salem, 1987), capillary electrophoresis (Peterson et al., 2002) and chromatography equipped with an electrochemical detection (Patel and Chau, 2008), chemiluminescence (Chen et al., 2007) and fluorescence (Fotopoulou and Ioannou, 2002). Among them high-performance liquid chromatography (HPLC) coupled to electrochemical detection offered advantages of high resolution with low detection limits (Holmes et al., 1994). A recent review summarizes and discusses all the analytical techniques above indicated and also describes how the detection of catecholamines and neurotransmitters is performed in real matrices (Perry et al., 2009).

\footnotetext{
* Corresponding author. Tel.: + 3906 72594405; fax: + 390672594328.

E-mail address: federica.valentini@uniroma2.it (F. Valentini).
}

Indeed, recently electrochemical methods were also used for the amperometric measurements of Ep, considering its electrochemical reactivity (Siangproh et al., 2011). Conventional bare electrodes suffered from a lower selectivity towards several catecholamines/neurotransmitters, as Dopamine (DA), Nor-Epineprhine (Nor-Ep) and Serotonin-5-HT (S-5HT). At the same time, Ascorbic (AA) and Uric (UA) acids exhibited, in the same potential window, a similar oxidation behavior of Ep and Ser-5-HT (Atta et al., 2010; Zare et al., 2005). Therefore, AA and UA represent two possible interferences for the electrochemical measurements of Ep. For this purpose, new chemically modified electrodes were studied to selectively measure Ep in a complex mixture, where other catecholamines or interferences were simultaneously present. Among all the chemically modified sensors, the most developed were those containing nanostructured materials. To this aim, carbon nanotubes (Shi et al., 2007; Shi et al., 2011a,b), carbon nanofibers (Wu et al., 2010), metallic nanoparticles (Atta et al., 2011), nanostructured polymers (Wang et al., 2004), nanocomposites (Lu et al., 2011), graphene (Cui and Zhang, 2012), and ionic liquids functionalized graphene (Valentini et al., 2013) were applied. Hybrid nanomaterials are also used for sensing enhancement (Shi et al., 2012, 2013). The novelty of this work is the choice of Single-Wall Carbon Nanohorns (SWCNHs) coupled with 
miniaturized SPEs. To the best of our knowledge, Single Wall Carbon Nanohorns were used only for the assembly of modified Glassy Carbon (GC) electrode in 2009, by Zhu et al. These latter were suitable for the simultaneous electrochemical detection of uric acid, dopamine, and ascorbic acid, with improvement in sensitivity of more than one order of magnitude especially for UA (Zhu et al., 2009). The choice of SWCNHs derives from their superior chemical-physical properties, that directly descend from the structure of this new metal free carbon based nanostructures, that is responsible for SWCNH's biocompatibility features (Miyawaki, et al., 2009). The structured dahlia flower-like aggregates (see Supporting information) derive from the assembling of several SWCNHs, whose average diameter is about $80 \mathrm{~nm}$. A detailed X-ray diffraction examination showed that the interhorn-wall distance was $0.4 \mathrm{~nm}$, being greater than the interlayer spacing of graphite $0.335 \mathrm{~nm}$ (Steele, 1974). Thus SWCNHs aggregates should have both microporosity and mesoporosity (Murata et al., 2000) originating from the above specific structure and very useful for sensors and actuators, electronic and electrochemical devices. In this work, SWCNHs-modified Screen-Printed Electrodes (SPEs) were assembled for a selective detection of Ep, in the presence of S-5HT, DA, Nor-Ep, AA, Ac and UA. The performance of such chemically modified sensor for Ep is strongly influenced by the surface chemistry, combined with the electrical p-type conductivity behavior (Urita et al., 2006; Yang et al., 2007) of the oxidized SWCNHs (Cioffi et al., 2007). Low detection limit, high sensitivity and a wide linear range of concentrations of Ep were thus obtained.

\section{Experimental}

\subsection{Apparatus}

Cyclic Voltammetry (CV), ChronoAmperometry (CA) and Differential Pulse Voltammetry (DPV) were carried out using an Autolab electrochemical system (Eco Chemie, Utrecht, The Netherlands) equipped with PGSTAT-12 and GPES software (Eco Chemie, Utrecht, The Netherlands), following the procedure described in ESI section. SPEs act as a miniaturized three-electrodes cell, incorporating a carbon based working electrode (3-mm diameter), a $\mathrm{Ag} / \mathrm{AgCl}$ pseudo-reference electrode, and a carbon counter/ auxiliary electrode. GC ( $\phi=3 \mathrm{~mm})$ bare electrode, used here for comparison, were from Amel, Milan (Italy). TG/DTA, Raman, XPS, FT-IR, BET and FE-SEM/EDAX apparatuses and sample preparation procedures were reported in Supporting information section.

\subsection{Materials}

Pristine SWNHs (p-SWCNHs) were produced by Carbonium s.r.l., Padova (Italy) by direct graphite evaporation in Ar flow, according to a patented method (Schiavon et al., 2004a,b) and used without purification. Oxidized SWCNHs (o-SWCNHs) were obtained following the procedure described in the Supporting information. Solvents and chemicals were purchased form Aldrich and used as received. All the experimental procedures were described in the Supporting information section.

\subsection{Preparation of SWCNHs modified SPES}

o- and p-SWCNH's dispersions were prepared in ethanolic medium at a concentration of $1 \mathrm{mg} / \mathrm{ml}$, and then treated in an ultrasonic bath for $3 \mathrm{~h}$. The so called o-SWCNHs/SPEs and p-SWCNHs/SPEs, were assembled by casting $5 \mu \mathrm{L}$ of SWCNHs dispersions on bare SPE, and waiting until the solvent evaporation. Electrochemical measurements were performed in drop detection mode as described in our previous paper (Valentini et al., 2013).

\section{Results}

\subsection{Characterization study of o-SWCNHS}

The chemical composition of the surface was investigated by means of the TG/DTA analysis (see ESI, Fig. S1 and Table S1) that demonstrates a functionalization of nanohorns (with a weight loss of 9.5\%), after the piranha treatment. This result was also confirmed by the Raman study (reported in details in ESI section, Fig. S2 and Table S2) where an increase of the $A_{D} / A_{G}$ bands was observed for o-SWCNHs, as compared with that recorded in presence of pristine nanomaterials (see Table S2), and confirmed here, by the XPS investigation. XPS broad scans, C1s and O1s spectra were recorded for both the pristine and oxidized materials. Fig. 1 reports the XPS results relevant to the chemical elemental analysis and to the surface speciation. The data there reported clearly indicate, as expected, that the oxidation process led to an increase of the oxygen amount on the surface of o-SWCNHs with respect to the pristine material. Then, the deconvolution of $\mathrm{C} 1 \mathrm{~s}$ XPS spectra of p-SWCNHs and o-SWCNHs was carried out (Fig. 1, top and bottom panel, respectively). In the top spectrum the strongest peak at $284.5 \pm 0.1 \mathrm{eV}$ was assigned to doubly bonded

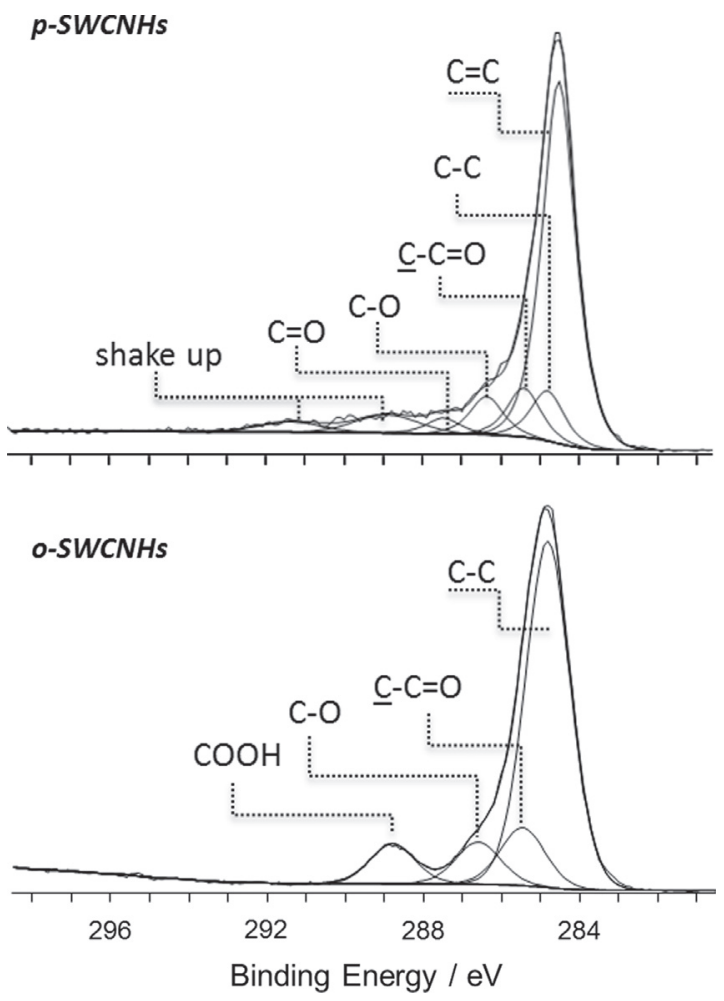

\begin{tabular}{cccc}
\multirow{2}{*}{ sample } & \multicolumn{2}{c}{ atomic \% } & O/C atomic ratio \\
\cline { 2 - 3 } & $\boldsymbol{C}$ & $\boldsymbol{O}$ & \\
\hline p-SWCNHs & $92.6 \pm 0.7$ & $7.4 \pm 0.7$ & $0.08 \pm 0.03$ \\
o-SWCNHs & $85.6 \pm 0.5$ & $14.4 \pm 0.5$ & $0.17 \pm 0.03$ \\
\hline
\end{tabular}

Fig. 1. C1s XPS spectra of p-SWCNHs (top panel) and o-SWCNHs (bottom panel) along with the peaks attribution. Table of the surface elemental composition and $\mathrm{O} / \mathrm{C}$ atomic ratio for p-SWCNHs and o-SWCNHs. The data were averaged out of five different analysis points and reported along with the associated standard deviation. 
a

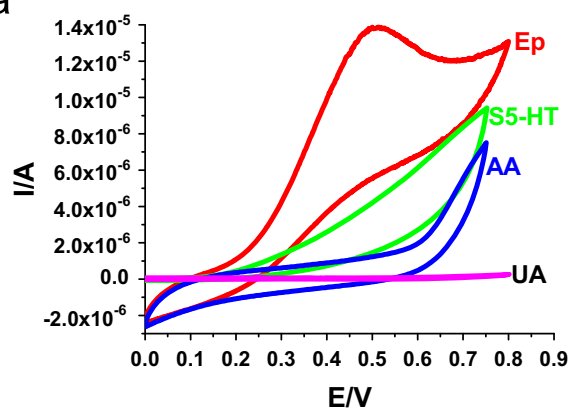

C

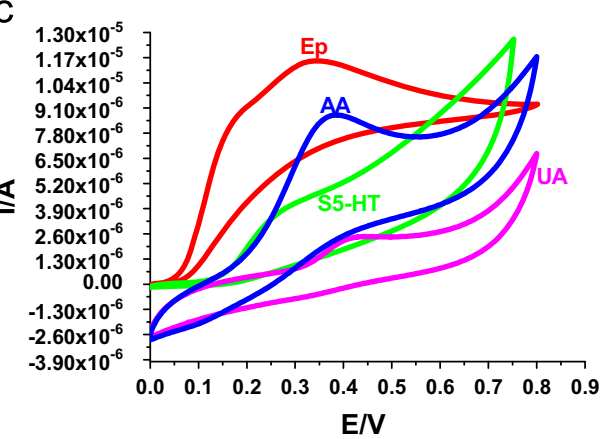

b

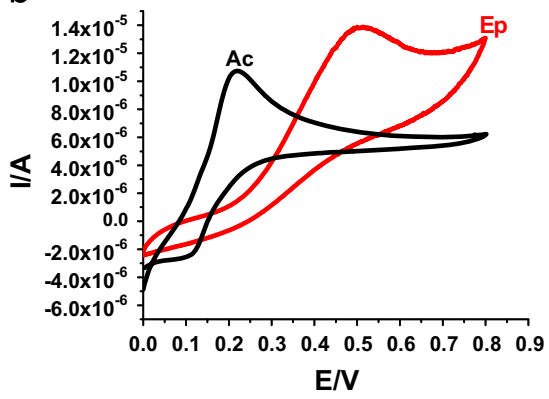

Table 1. Electrochemical parameters from $\mathrm{CV}$

\begin{tabular}{|c|c|c|c|c|}
\hline \multirow{2}{*}{$\begin{array}{c}\text { Molecular } \\
\text { targets }\end{array}$} & \multicolumn{3}{|c|}{ Bare SPE } & \multicolumn{2}{c|}{ o-SWCNH/SPE } \\
\cline { 2 - 5 } & $\mathrm{E}_{\mathrm{p}} / \mathrm{V}$ & $\mathrm{I}_{\mathrm{pa}} / \mu \mathrm{A}$ & $\mathrm{E}_{\mathrm{p}} / \mathrm{V}$ & $\mathrm{I}_{\mathrm{pa}} / \mathrm{A}$ \\
\hline $\mathrm{Ep}$ & +0.35 & +12.0 & +0.50 & +1.40 \\
\hline $\mathrm{S} 5-\mathrm{HT}$ & +0.25 & +3.00 & n.d.p. $^{*}$ & n.d.p. $^{*}$ \\
\hline $\mathrm{AA}$ & +0.35 & +9.10 & n.d.p. $^{*}$ & n.d.p. $^{*}$ \\
\hline Ac & $+0.30^{\text {a }}$ & $+10.0^{\text {a }}$ & 0.22 & 10.0 \\
\hline UA & +0.40 & +1.30 & n.d.p. $^{*}$ & n.d.p. $^{*}$ \\
\hline *n.d.p. $=$ not detectable peaks by Autolab PGStat12 for CV technique; ${ }^{\text {a: }}$ for Ac, see ESI
\end{tabular}

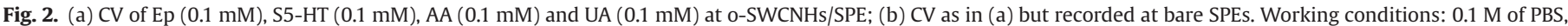
at $\mathrm{pH}$ 7.4. Scan rate: $100 \mathrm{mV} / \mathrm{s}$; and finally (c): CV of Ep $(0.1 \mathrm{mM})$ and Ac $(0.1 \mathrm{mM})$ at o-SWCNHs/SPE.

carbons $(C=C)$ (Utsumi et al., 2007), according to the structure of graphene forming the NHs. Further peaks with lower intensity were also observed in the higher binding energy region: $\mathrm{C}=\mathrm{O}$ at $287.5 \pm 0.1 \mathrm{eV}, \mathrm{C}-\mathrm{O}$ at $286.4 \pm 0.1 \mathrm{eV}, \mathrm{C}-\mathrm{C}=\mathrm{O}$ at $285.4 \pm 0.1 \mathrm{eV}$ and singly bonded carbons $(\mathrm{C}-\mathrm{C})$ at $284.8 \pm 0.1 \mathrm{eV}$. The signals in the region between $289 \mathrm{eV}$ and $292 \mathrm{eV}$ were interpreted as shake up features associated to $\pi \rightarrow \pi^{*}$ transition, very intense due to the large amount of $\mathrm{sp}^{2}$ hybrid orbitals. In the $\mathrm{C} 1 \mathrm{~s}$ spectrum of o-SWCNHs the deconvolution resulted in only four peaks: the most intense at $284.8 \pm 0.1 \mathrm{eV}$ assigned to $\mathrm{C}-\mathrm{C}$, and the others attributed to oxygen-containing functional groups $(\mathrm{C}-\mathrm{C}=\mathrm{O}$ at $285.5 \pm 0.3 \mathrm{eV}, \mathrm{C}-\mathrm{O}$ at $286.6 \pm 0.1 \mathrm{eV}$ and $\mathrm{COOH}$ at $288.8 \pm 0.1 \mathrm{eV}$ ). Therefore, combining all the results, two important pieces of information can be deduced: first of all the oxidation process of the NHs led to an increase of the oxygenated groups (see $\mathrm{O} / \mathrm{C}$ ratio in the table of Fig. 1 ). Moreover, the absence of shake up signals in the XP spectrum of o-SWCNHs suggested a likely complete saturation of the carbon double bonds, at least on the top surface of the material.

FT-IR studies (reported in Fig. S3, in ESI), were performed on the same samples. The FT-IR profiles were quite similar for both samples, but the o-SWCNHs display new absorption bands, centered at 1386, 1439, 1657, 1722 and $1757 \mathrm{~cm}^{-1}$. In particular, these last bands are due to the presence of carboxylic acids (also confirmed by the presence of the adsorption band of the $\nu \mathrm{O}-\mathrm{H}$, centered at $3430 \mathrm{~cm}^{-1}$ ), esters, aldehydes and ketones (Yuge et al., 2008). Another important aspect to consider in o-SWCNH's spectrum is the disappearance of the typical adsorption signals at 3013 and $2918 \mathrm{~cm}^{-1}$, which were present in p-SWCNH's spectrum. These bands are due to the stretching modes of the $\mathrm{C}-\mathrm{H}$ groups present in p-SWCNH's structure, which disappeared after oxidation because both functional groups, $\mathrm{C}-\mathrm{H}$ and $\mathrm{Csp}^{2}$ are the main catalytic centers where the oxidation processes occurred, respectively. p-SWCNH's spectrum also revealed the interesting adsorption bands registered at $1149 \mathrm{~cm}^{-1}$ related to the presence of oxygenated functional groups, which indicate that also p-SWCNHs are partially oxidized.

\subsection{Electrochemical characterization}

Fig. 2a reports the CV plots for Ep, S-5HT, AA and UA recorded at o-SWCNH/SPEs, while, for comparison purposes Fig. 2b reports the profiles observed with bare SPE, where a complete overlap of all the oxidation peaks was clearly evident (and similarly on pristine SWCNHs and GC bare electrode, see ESI, Fig. S4). The morphological and topographic characterization study of the modified o-SWCNH/ SPE surfaces was also carried out and clearly reported in Fig. S5, in ESI. After the modification, performed with o-SWCNHs, an homogeneous and uniform layer was observed on the SPE working electrode surface, with an increase of the roughness of the corresponding modified electrodes. This result very well agreed with the additional BET data and also with the electrochemical area ones (Bard and Faulkner, 1980), both higher that the value recorded in the case of the geometric area (see Table S4). Furthermore Fig. 2c shows comparison of Ep and Ac with o-SWCNH/SPEs. To note, Ac is a neutral molecule and it exhibits an irreversible oxidation peak centered around $+0.200 \mathrm{~V}$, at o-SWCNH/SPEs. Thus not interfering with Ep, which was positively charged in this $\mathrm{pH}$ conditions, ${ }^{1}$ showing a very well resolved oxidation peak, centered at about $+0.500 \mathrm{~V}$, where the involvement of $\mathrm{H}^{+}$in the oxidation reaction of Ep was also confirmed by the formal potential $v s$. pH plot (see ESI, Fig. S6), according to the literature (Hernandez et al., 1998). In Fig. 2a, where SPEs are modified by using o-SWCNHs only the oxidation peak of Ep was clearly visible. To explain the Ep signal here, the surface chemistry of o-SWCNHs should be considered. o-SWCNHs, results negatively charged for the presence of carboxylates anions, at the working $\mathrm{pH}=7.4$, in $0.2 \mathrm{M}$ of PBS. In fact, preliminary Z-potential/DLS study indicates a value of ca. $-18 / \mathrm{mV}$ consistent with an overall negative charge distribution on the o-SWCNHs, having hydrodynamic diameters of $\sim 200 \mathrm{~nm}$, for the presence of aggregates in liquid PBS medium. On the other hand, in the

\footnotetext{
${ }^{1}$ At $\mathrm{pH}$ 7, epinephrine exists in its cationic form $\left(\mathrm{p} K_{\mathrm{a}}=9.9\right)$ (Dempsey et al. 2003; Łuczak, 2008) while ascorbic acid $\left(\mathrm{p} K_{\mathrm{a}}=4.1\right)$ and uric acid $\left(\mathrm{p} K_{\mathrm{a}}=5.4\right)$ in their anionic form (Jiang and Lin, 2005).
} 

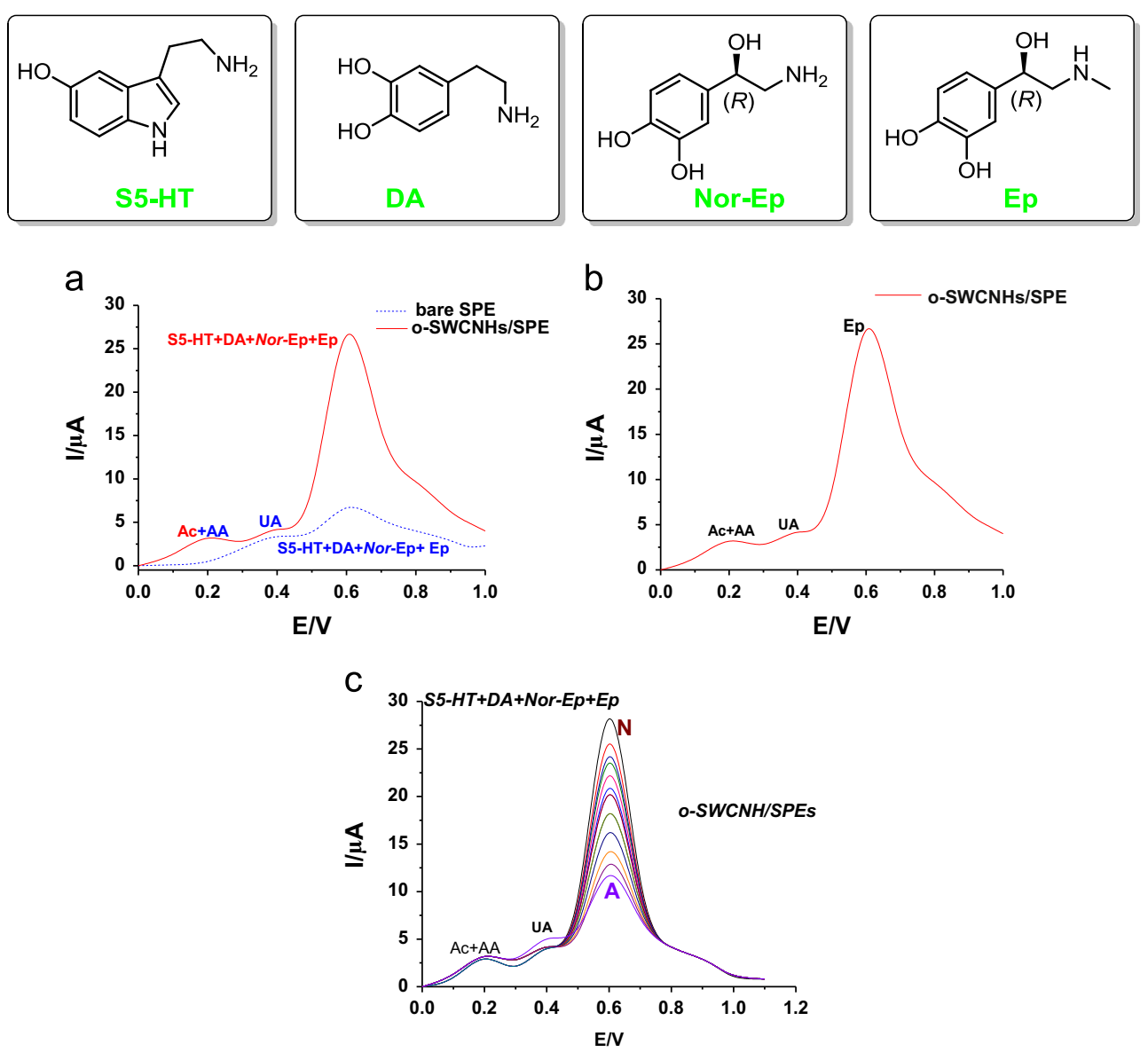

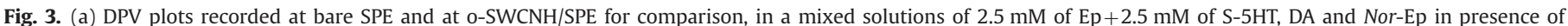

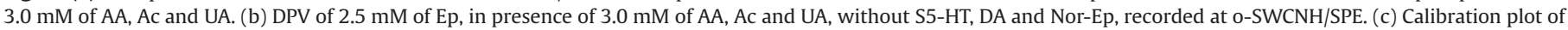

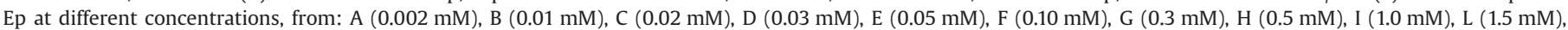

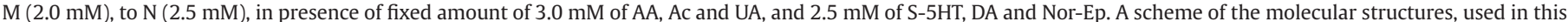
study, has been also reported at the top of this figure.

same experimental conditions, p-SWCNHs exhibited a Z-potential value of ca. $+24 / \mathrm{mV}$ and hydrodynamic diameters, ranging from 30 to $70 \mathrm{~nm}$, according to the literature (Xu et al., 2010; Huang et al., 2011). In this respect, the positively charged Ep was clearly attracted on o-SWCNH/SPE surface. Conversely, AA and UA, which are negatively charged at the same working conditions, are electrostatically rejected and therefore no signals have been obtained at modified SPE-working electrodes. This result confirms the presence of a double layer-capacitance on the o-SWCNH/SPEs $\left(14.4 \mu \mathrm{F} / \mathrm{cm}^{2}\right)$, more evident than that recorded in the case of p-SWCNH/SPEs $\left(4.90 \mu \mathrm{F} / \mathrm{cm}^{2}\right)$. On the other hand, S-5HT does not show any oxidation peak likely because of at conventional scan rates, an insulating film forms on the electrode after electrochemical-oxidation, thus preventing the detection on subsequent scans (Ewing et al., 1981). Similarly, Dopamine (DA) and Nor-Ep, did not exhibit good electrochemical profiles (see Fig. S4e and f, in ESI, respectively). This result is promising to assemble a selective, disposable, miniaturized chemically modified sensors for a quantitative detection of Ep, likely applicable for "in vivo" systems. Probably in the future, a mixture of all catecholamines could be simultaneously detected if in presence of a fast scan CV mode (Nakazato and Akiyama, 1999) in patients affected by neurological diseases (Shankaran and Miura, 2007; Ivankin and Wanunu, 2012).

\subsection{Highly selective electrochemical detection of Ep}

DPV profiles of Ep, S-5HT, DA, Nor-Ep, AA, Ac and UA recorded at $\mathrm{o}-\mathrm{SWCNH} / \mathrm{SPES}$ and at bare SPE are reported in Fig. 3.
At o-SWCNHs modified electrodes with DPV, a very well resolved peak $(+0.500 \mathrm{~V})$ for Ep was obtained (Fig. 3a); while Ser-5HT, DA, Nor-Ep, AA and UA do not exhibit significant oxidation signals. On the other hand, working at SPE bare electrodes by DPV, all the analytes showed broad and overlapped peaks around $+0.500 \mathrm{~V}$, similarly to what is shown by the CV plots. Fig. 3b shows the specific oxidation peak for Ep, in the presence of AA, Ac and UA but without S-5HT, DA and Nor-Ep. In ESI section, Fig. S7 clearly evidenced that the signal recorded at $+0.6 \mathrm{~V}$ is only related to the Ep oxidation, when Ep is present alone in the solution, without AA, AC and UA. This result confirms that the DPV signal shown in Fig. 3a was only due to Ep and not to a simultaneous detection of S-5HT, DA, Nor-Ep and Ep. The corresponding DPV calibration plot is reported in Fig. 3c while all the analytical parameters were highlighted in Tables S5 and S6 and in Fig. S8. The o-SWCNHs/SPEs showed excellent analytical performances in terms of wider linear concentration range and higher sensitivity, if compared with other electrochemical devices modified by different carbonaceous nanostructured materials, described in literature (reported in Table S5, for comparison with the appropriate references). Moreover, in comparison with other modified transducers assembled with metallic nanoparticles and nanocomposites, the analytical performances of o-SWCNH/SPEs, toward Ep detection resulted also with a better sensitivity, faster response time and larger linear concentration range, even though higher LOD as shown in Table S6. The selective molecular recognition of Ep vs. S5-HT, DA and Nor-Ep on o-SWCNH/SPEs may be ascribed to a favorable interplay of effects resulting from the chemical modification of the SWCNH 
surface, fostering an increased surface area (see ESI for BET data). The best response of Ep could depend on its molecular structure (see Fig. 3) where probably the speed of the keto-enol tautomerism does not allow the formation of intermediates during the electro-oxidation (Brad et al., 1995; Nakazato and Akiyama, 1999), which irreversibly adsorb on the surface of the transducer (not allowing more selective determination of analytes during the subsequent scans cycles, contrary to what happens for all the other catecholamines (Kalyanaraman et al., 1987)).

\section{Conclusions}

SWCNHs were used to modify SPEs. The presence of oxygenated functionalities on SWCNH's surface control their p-type conductivity behavior and also their electrochemical reactivity toward different electro-active species. The organic functionalities produce a double layer-capacitance on o-SWCNHs/SPEs working area, that induces an electrostatic barrier toward the negatively charged interferences, giving a higher Signal/to Noise ratio only for epinephrine-neurotransmitter. In order to detect Ep in the presence of these common interferences, we propose to use the DPV method that makes a desirable Signal/Noise ratio for Ep in presence of S-5HT, AA and UA. The chemical functionalization of the carbon nanostructures is pivotal to achieve an oustanding analyte selectivity. This observation opens the way to a tailored fabrication of the electrodic nano-material and it will be further addressed in future studies also in real matrices with the aid of fast scan CV mode.

\section{Appendix A. Supporting information}

Supplementary data associated with this article can be found in the online version at http://dx.doi.org/10.1016/j.bios.2014.02.065.

\section{References}

Atta, N.F., Galal, A., Abu-Attia, F.M., Azaba, S.M., 2011. J. Mater. Chem. 21, 13015-13024.

Bard, A.J., Faulkner, L.R., 1980. In: Bard, A.J., Faulkner, L.R., (Eds.), Electrochemical Methods: Fundamentals and Applications. John Wiley \& Sons, Inc., New York, pp. 370-428.

Brad, P.J., Dietz, S.M., Wightman, R.M., 1995. Anal. Chem. 67, 1115-1120.

Chen, F.N., Zhang, Y.X., Zhang, Z.J., 2007. Chin. J. Chem. 25, 942-946.

Cui, F., Zhang, X., 2012. J. Electroanal. Chem. 669, 35-41.
Dempsey, E.A., Kennedy, N.F., McCormac, T., 2003. Electroanalysis 15, 1835. Dongen, P.A.M., 1981. Prog. Neurobiol.17, 97-139.

Ewing, A.G., Dayton, M.A., Wightman, R.M., 1981. Anal. Chem. 53, 1842-1847.

Fotopoulou, M.A., Ioannou, P.C., 2002. Anal. Chim. Acta 462, 179-185.

Hernandez, P., Sanchez, I., Paton, F., Hernandez, L., 1998. Talanta 46, 985.

Holmes, C., Eisenhofer, G., Goldstein, D.S., 1994. J. Chromatogr. B Biomed. Sci. Appl. 653, 131-138.

Huang, W., Zhang, J., Dorn, H.C., Geohegan, D., Zhang, C., 2011. Bioconjugate Chem. 22, 1012-1016.

Ivankin, A., Wanunu, M., 2012. Nanomedicine 7, 1479-1481.

Jiang, X., Lin, X., 2005. Analyst 130, 391.

Kalyanaraman, B., Premovic, P.I., Sealy, R.C., 1987. J. Biol. Chem. 262, 11080-11087.

Lu, Xiaoquan, Li, Yaya, Du, J., Zhou, X., Xue, Z., Liu, X., Wang, Z., 2011. Electrochim. Acta 56, 7261-7266.

Łuczak, T., 2008. Electroanalysis 20, 1317-1322.

Miyawaki, J., Matsumura, S., Yuge, R., Murakami, T., Sato, S., Tomida, A., Tsuruo, T., Ichihashi, T., Fujinami, T., Irie, H., Tsuchida, K., Iijima, S., Shiba, K., Yudasaka, M. 2009. ACS Nano 3 (6), 1399-1406.

Murata, K., Kaneko, K., Kokai, F., Takahashi, K., Yudasaka, M., Iijima, S., 2000. Chem. Phys. Lett. 331, 14-20.

Nakazato, T., Akiyama, A., 1999. J. Neurosci. Methods 89, 105-110.

Patel, B.A. Chau, R.M.W., 2008. Biomed. Chromatogr. 23, 175-181.

Perry, M., Li, Qiang, Kennedy, R.T., 2009. Anal. Chim. Acta 653, 1-22.

Peterson, Z.D., Collins, D.C., Bowerbank, C., R Lee, M.L., Graves, S.W., 2002 J. Chromatogr. B 776, 221-229.

Remy, F., Mirrashed, F., Campbell, B., Richter, W., 2005. NeuroImage 25, 253-266.

Salem, F.B., 1987. Talanta 34, 810-812.

Schiavon, M., 2004a. Device and Method for Production of Carbon Nanotubes, Fullerene and Their Derivatives. European Patent EP1428794 (A2).

Schiavon, M., 2004b. Device and Method for Production of Carbon Nanotubes, Fullerene and Their Derivatives. European Patent E2004213727 (A1)

Shankaran, D.R., Miura, N., 2007. Recent Pat. Nanotechnol. 1 (14), 210-223.

Siangproh, W., Dungchai, W., Rattanarat, P., Chailapakul, O., 2011. Anal. Chim. Acta 690, 10-25.

Steele, W.A., 1974. The Interaction of Gases with Solid Surface. Pergamon, Oxford

Shi, J., Cha, T.G., Claussen, J.C., Diggs, A.R., Choi, J.H., Marshall, P.D., 2011a. Analyst 136, 4916-4924.

Shi, J., Claussen, J.C., McLamore, E.S., Haque, A., Jaroch, D., Diggs, A.R., Calvo-Marzal, P., Rickus, J.L., Porterfield, D.M., 2011b. Nanotechnology 22 (35), 355502.

Shi, J., Zhang, H., Snyder, A., Wang, M.-X., Xie, J., Porterfield, D.M., Stanciu, L.A., 2012 Biosens. Bioelectron. 38, 314-320.

Shi, J., McLamoree, E.S., Porterfield, D.M., 2013. Biosens. Bioelectron. 40, 127-134.

Urita, K., Seki, S., Utsumi, S., Noguchi, D., Kanoh, H., Tanaka, H., Hattori, Y., Ochiai, Y., Aoki, N., Yudasaka, M., Iijima, S., Kaneko, K., 2006. Nano Lett. 6, 1325-1328.

Utsumi, S., Honda, H., Hattori, Y., Kanoh, H., Takahashi, K., Sakai, H., Abe, M. Yudasaka, M., Iijima, S., Kaneko, K., 2007. J. Phys. Chem. C 111, 5572-5575.

Valentini, F., Carbone, M., Palleschi, G., 2013. Anal. Bioanal. Chem. 405, 3449-3474. Wang, H.S., Huang, D.Q., Liu, R.M., 2004. J. Electroanal. Chem. 570, 83-90.

Wu, Y., Mao, X., Cui, X., Zhu, L., 2010. Sens. Actuators B 145, 749-755.

Xu, J., Iijima, S., Yudasaka, M., 2010. Appl. Phys. A 99, 15-21.

Yang, C.M., Kim, Y.J., Endo, M., Kanoh, H., Yudasaka, M., Iijima, S., Kaneko, K., 2007 J. Am. Chem. Soc. 129, 20-21.

Yuge, R., Zhang, M., Tomonari, M., Yoshitake, T., Iijima, S., Yudasaka, M., 2008. ACS Nano 2, 1865-1870.

Zare, H.R., Nasirizadeh, N.M., Ardakani, M., 2005. Electroanal. Chem. 577, 25-33.

Zhu, S., Haijuan, L., Niu, W., Xu, G., 2009. Biosens. Bioelectron. 25, 940-943. 